\title{
Highly Regioselective Direct C-H Arylation: Facile Construction of Symmetrical Dithienophthalimide-Based $\pi$-Conjugated Molecules for Optoelectronics
}

\author{
Xiang-Chun Li, ${ }^{1}$ Yibo Xue, ${ }^{1}$ Wan Song, ${ }^{1}$ Yu Yan, ${ }^{1}$ Jie Min, ${ }^{1}$ Fang Liu, ${ }^{1}$ Xu Liu, ${ }^{1}$ \\ Wen-Yong Lai $i^{1},{ }^{1,2}$ and Wei Huang ${ }^{1,2}$ \\ ${ }^{1}$ Key Laboratory for Organic Electronics and Information Displays, Institute of Advanced Materials (IAM), Nanjing University of \\ Posts \& Telecommunications, 9 Wenyuan Road, Nanjing 210023, China \\ ${ }^{2}$ Frontiers Science Center for Flexible Electronics, Xi'an Institute of Flexible Electronics (IFE) and Xi'an Institute of Biomedical \\ Materials \& Engineering, Northwestern Polytechnical University, 127 West Youyi Road, Xi'an 710072, China
}

Correspondence should be addressed to Wen-Yong Lai; iamwylai@njupt.edu.cn

Received 16 April 2020; Accepted 26 July 2020; Published 30 August 2020

Copyright (C) 2020 Xiang-Chun Li et al. Exclusive Licensee Science and Technology Review Publishing House. Distributed under a Creative Commons Attribution License (CC BY 4.0).

Controllable direct C-H arylation with high regioselectivity is highly desirable yet remains a formidable challenge. Herein, a facile regioselective direct $\mathrm{C}-\mathrm{H}$ arylation is developed for efficient construction of a variety of symmetrical dithienophthalimide-based $\pi$ conjugated molecules. The resulting methodology is applicable to a wide range of substrates, from electron-rich units to electrondeficient units with large steric end groups. Aryl halides have been confirmed to be able to couple with dithienophthalimide (DTI) via direct $\mathrm{C}-\mathrm{H}$ arylation, showing high regioselectivity. Varying the functional end groups onto the DTI core has been demonstrated to fine tune the emission colors to cover most of the visible spectra. The results suggest a facile strategy towards highly selective direct $\mathrm{C}-\mathrm{H}$ arylation, opening the prospects towards efficient construction of $\pi$-conjugated molecules for various potential optoelectronic applications.

\section{Introduction}

Organic $\pi$-conjugated molecules have been intensively explored over recent years for various potential applications, i.e., as active materials for organic light-emitting diodes (OLEDs) [1-7], organic photovoltaics [8-10], organic fieldeffect transistors [11-14], organic semiconductor lasers [1519], theranostics [20-22], etc. The construction of organic conjugated molecules depends on the efficient formation of the carbon-carbon bond between two $\mathrm{sp}^{2}$ carbons [23-27]. For this purpose, a variety of carbon-carbon cross-coupling reactions, such as Suzuki, Stille, Heck, and Kumada reactions, have thus been widely explored for the couplings of aryl halides with the toxic intermediates (organometallic/boride heteroaromatics) [28-33]. In contrast, direct $\mathrm{C}-\mathrm{H}$ arylation overcomes the use of toxic intermediates and simplifies the reaction process, which has emerged most recently as a simple, atom-efficient, and ecofriendly methodology for constructing conjugated molecules, especially for those containing electron-deficient moieties [34-39]. Due to the intrinsic electron affinity of electron-deficient moieties, it is generally quite challenging to obtain suitable active intermediates for Suzuki or Stille cross-coupling reactions, since the resulting nucleophilic addition of electron-deficient acceptors would often cause subsequent decomposition [40-43]. Direct C-H arylation offers an effective methodology for the functionalization of electron-deficient moieties without electrophilic substitution or strongly nucleophilic intermediates. To date, only quite a limited number of electron-deficient moieties have been reported to be suitable for direct $\mathrm{C}-\mathrm{H}$ arylation such as benzothiadiazoles (BT) [44], thienopyrazines (TPz) [45], and thienopyrrolediones (TPD) (Scheme 1) [46]. In order to construct diverse organic $\pi$-conjugated molecules as efficient active materials for various potential applications, the screening 

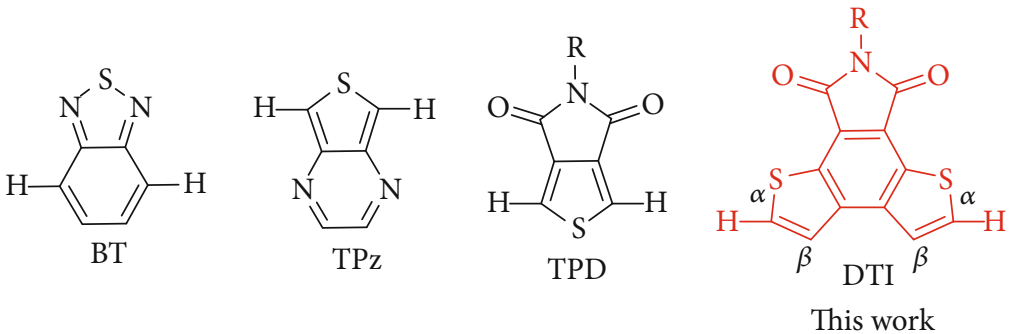

Scheme 1: Chemical structures of benzothiadiazoles (BT), thienopyrazines (TPz), thienopyrrolediones (TPD), and dithienophthalimides (DTI).

and development of novel building blocks especially those with electron-deficient moieties suitable for direct C-H arylation are preferred but challenging.

For direct $\mathrm{C}-\mathrm{H}$ arylation, the regioselectivity is a critical issue since the diverse $\mathrm{C}-\mathrm{H}$ groups may lead to the formation of a variety of isomers and structural defects [47-50]. The isomers and structural defects may increase the difficulty of separating the mixture of the products, which would induce structural uncertainty and may deteriorate the physical properties [51-53]. When considering crosscoupling reactions, it should be noted that structural defects, i.e., isomerization or branching, cannot be eliminated by subsequent purification because they are usually chemically embedded in the chemical structures, which would normally limit the physical performance for optoelectronic applications mainly due to the chemical impurity. Even a small number of structural defects could result in a sharp decline in the optoelectronic characteristics [54-56]. For these reasons mentioned above, the selectivity and regioselectivity issues have been considered the Achilles heel of $\mathrm{C}-\mathrm{H}$ arylation. Although a variety of direct $\mathrm{C}-\mathrm{H}$ arylation has been explored [34-39, 44-46], the selective direct C-H arylation reactions are still relatively rare [50, 57-59]. Controllable direct $\mathrm{C}-\mathrm{H}$ arylation with high selectivity and regioselectivity is thus highly desirable yet remains a formidable challenge.

Here, we report a highly regioselective direct $\mathrm{C}-\mathrm{H}$ arylation based on a new fused-ring electron-deficient dithienophthalimide (DTI) building block and afford a series of symmetrical DTI-based conjugated molecules (Scheme 2). This work includes the optimization of reaction parameters and the adjustment of emission spectra of the $\pi$-conjugated materials in the solid films with a broad scope ranging from $400 \mathrm{~nm}$ to $780 \mathrm{~nm}$. The aromatic halides were successfully converted into target diarylated DTI derivatives with high yields. The general potential of this reaction has been studied by using several aryl substituents such as electron-rich groups (fluorene, pyrene, carbazole and triphenylamine), electron-deficient groups (naphthalene diimide, perylene diimide), and large steric groups (mesitylene) (Scheme 2). Interestingly, direct C-H arylation based on DTI shows excellent regioselectivity as compared with traditional Suzuki or Stille cross-coupling routes. All the DTI-based $\pi$-conjugated molecules are easy to synthesize and functionalize in a practical, high yield, and selective synthetic pathway, which is beneficial for establishing a library of organic optoelec- tronic materials with emission wavelengths covering most of the visible spectra. The high isolated yields of diarylated products suggest that $\mathrm{C}-\mathrm{H}$ activation is feasible and effective to construct DTI-based conjugated molecules. Furthermore, DTI2F and DTI2CzR based on DTI with fluorene and carbazole functional end groups exhibit high fluorescence quantum efficiency of $59 \%$ and $67 \%$, respectively. Preliminary OLEDs based on DTI2F demonstrated promising device characteristics with the maximum current efficiency of $3.8 \%$ and the maximum brightness of $7200 \mathrm{~cd} / \mathrm{m}^{2}$ at $11 \mathrm{~V}$. The results suggest a facile strategy towards highly selective direct $\mathrm{C}-\mathrm{H}$ arylation for the efficient construction of various $\pi$-conjugated molecules based on DTI for optoelectronic applications.

\section{Results}

2.1. Synthetic Optimization. Scheme S1 depicts the synthesis route of DTI. Optimization of reaction conditions was carried out by using DTI and bromomesitylene (BrMes) as C-H arylation substrates. The ligands in tetrahydrofuran (THF) were prescreened before the synthetic study (Table 1). Among various ligands, $\mathrm{P}(2-\mathrm{MeOPh})_{3}$ was proven to be effective to afford the target material DTI2Mes with an isolated yield of $30 \%$. The stronger base $\mathrm{Cs}_{2} \mathrm{CO}_{3}$ resulted in a higher yield (33\%, entry 5). When the catalyst $\mathrm{Pd}(\mathrm{OAc})_{2}$ changed to $\mathrm{Pd}_{2}(\mathrm{dba})_{3}$, the yield of DTI2Mes was further raised to $44 \%$. Moreover, under the same conditions, a higher yield of DTI2Mes was obtained with using direct C-H arylation in 0 xylene ( $84 \%$, Table 1 , entry 9$)$. In each entry of Table 1 , only a monosubstituted byproduct was obtained. Excessive BrMes (3 equiv.) was used to inhibit side reactions.

Investigation of the (hetero)aryl bromide substrate was carried out by optimizing the reaction conditions: $\mathrm{Pd}_{2}(\mathrm{dba})_{3}$ ( 0.03 equiv.), $\mathrm{P}(2-\mathrm{MeOPh})_{3}$ ( 0.12 equiv.), $\mathrm{PivOH}$ ( 1.0 equiv.), and $\mathrm{Cs}_{2} \mathrm{CO}_{3}$ (3.0 equiv.) in $o$-xylene at $120^{\circ} \mathrm{C}$ for $24 \mathrm{~h}$. Under the optimized conditions, the substrate (BrMes) with large steric hindrance groups was successfully coupled with DTI to afford product DTI2Mes in high yields (84\%). Then, representative electron-rich groups including fluorene, pyrene, carbazole, and triphenylamine were examined to afford donor-acceptor type conjugated molecules in moderate to good isolated yields (58-72\%). However, when using electron-rich bromothiophenes as the reaction substrates, only trace target compounds were obtained mainly due to 


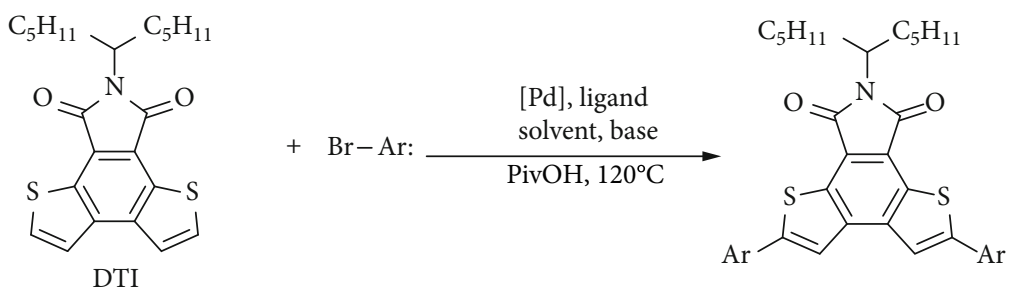<smiles>[R]C(Br)c1cccc2c1c1ccccc1n2-c1ccc(Br)cc1</smiles><smiles>Brc1ccc(N(c2ccccc2)c2ccccc2)cc1</smiles>

$(72 \%)$

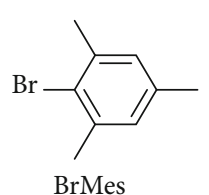

$(84 \%)$<smiles>BrCc1ccsc1Br</smiles>

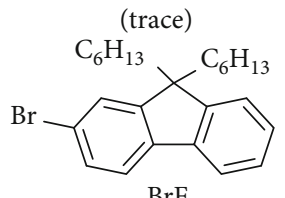

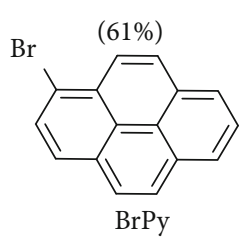

$(54 \%)$

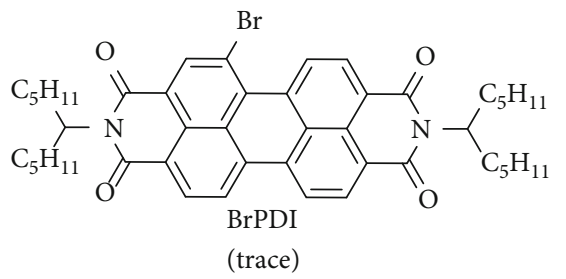<smiles>[R]N1C(=O)C2=C(c3ccc(Br)s3)N([R7]([H])c3ccccc3)C(=O)C2=C1c1cccs1</smiles>

(trace)

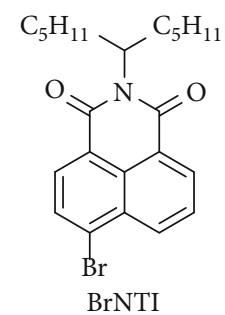

$(63 \%)$

Scheme 2: Synthetic routes toward conjugated materials based on DTI by direct C-H arylation with various aryl brominated substituents.

the undesired homocoupling reactions and debromination byproducts of bromothiophenes. The reaction yield of DTI with $\mathrm{BrCz}$ was lower than that of its derivative $(\mathrm{BrCzR})$, due to the existence of $\mathrm{NH}$ reactive groups in carbazole molecules which are prone to nucleophilic substitution. Subsequently, examination of the substrate scope was extended to electron-deficient (hetero)aryl bromides (BrPDI, BrDPP, and BrNTI). Unfortunately, we failed to isolate pure products DTI2PDI and DTI2DPP because of the quite low yields. DTI2NTI with naphthalimide (NTI) as acceptor-type end groups was successfully obtained at a $63 \%$ yield. The favorable isolated yields of different substrates for the diaryl products suggest that direct $\mathrm{C}-\mathrm{H}$ arylation is an attractive synthetic methodology for the construction of diverse organic $\pi$-conjugated molecules based on DTI.

2.2. Regioselectivity of $\mathrm{C}-\mathrm{H}$ Arylation Based on DTI. C-H arylation with poor selectivity is often considered to be a detrimental side reaction in constructing organic $\pi$-conjugated molecules, which would subsequently limit the optoelectronic performance. Generally, it is difficult for the substrates with multiple $\mathrm{C}-\mathrm{H}$ bonds to carry out selective $\mathrm{C}-\mathrm{H}$ arylation, and the reaction conditions are also critical to determine the reactivity of the protons. Surprisingly, the $\mathrm{C}-\mathrm{H}$ arylation based on DTI exhibits quite high selectivity. Although the reaction was also carried out through traditional Suzuki or Stille cross couplings, it was not applicable to construct selective DTI-based conjugated molecules due to the difficulty in purifying the dibrominated DTI (Scheme 3). As shown in the ${ }^{1} \mathrm{H}$ NMR of $2 \mathrm{BrDTI}$ (Figure S2), there were three isomers which appeared to be very difficult to isolate separately from the resulting products. In addition, the isolated yield of $2 \mathrm{BrDTI}$ was rather low ( $10 \%)$, since monobromo-, tribromo-, and tetrabromosubstituted DTI byproducts were formed. However, in ${ }^{1} \mathrm{H}$ NMR spectra of DTI2Mes synthesized by $\mathrm{C}-\mathrm{H}$ arylation, all signals were clearly assigned, further corroborating the high regioselectivity of the direct $\mathrm{C}-\mathrm{H}$ arylation based on DTI (Figure 1). The aromatic region of DTI2Mes (7.03-7.48 ppm) obtained by $\mathrm{C}-\mathrm{H}$ arylation showed no other signals, while it showed five aromatic protons signals in this region as compared with that of DTI2Mes-mix synthesized by traditional cross couplings. Obviously, there were no other isomers generated during $\mathrm{C}-\mathrm{H}$ arylation. According to the NMR data, no additional diaryl-substituted isomers were obtained except symmetrical DTI2Mes via $\mathrm{C}-\mathrm{H}$ arylation. In 
TABLE 1: Conditions and yields for the direct C-H arylation with various brominated substituents.

\begin{tabular}{|c|c|c|c|c|c|c|c|}
\hline Entry & Compound & $\mathrm{Br}-\mathrm{Ar}$ & {$[\mathrm{Pd}]^{\mathrm{a}}$} & Ligand $^{\mathrm{a}}$ & Base $^{\mathrm{a}}$ & Solvent $^{\mathrm{a}}$ & Yield (\%) \\
\hline 1 & DTI2Mes & BrMes & $\mathrm{Pd}(\mathrm{OAc})_{2}$ & $\mathrm{PCy}_{3}$ & $\mathrm{~K}_{2} \mathrm{CO}_{3}$ & THF & Trace \\
\hline 2 & DTI2Mes & BrMes & $\mathrm{Pd}(\mathrm{OAc})_{2}$ & $\mathrm{PPh}_{3}$ & $\mathrm{~K}_{2} \mathrm{CO}_{3}$ & THF & 14 \\
\hline 3 & DTI2Mes & BrMes & $\mathrm{Pd}(\mathrm{OAc})_{2}$ & $\mathrm{P}(o-\mathrm{Tol})_{3}$ & $\mathrm{~K}_{2} \mathrm{CO}_{3}$ & THF & 19 \\
\hline 4 & DTI2Mes & BrMes & $\mathrm{Pd}(\mathrm{OAc})_{2}$ & $\mathrm{P}(2-\mathrm{MeOPh})_{3}$ & $\mathrm{~K}_{2} \mathrm{CO}_{3}$ & THF & 30 \\
\hline 5 & DTI2Mes & BrMes & $\mathrm{Pd}(\mathrm{OAc})_{2}$ & $\mathrm{P}(2-\mathrm{MeOPh})_{3}$ & $\mathrm{Cs}_{2} \mathrm{CO}_{3}$ & THF & 33 \\
\hline 6 & DTI2Mes & BrMes & $\mathrm{Pd}_{2}(\mathrm{dba})_{3}$ & $\mathrm{P}(2-\mathrm{MeOPh})_{3}$ & $\mathrm{Cs}_{2} \mathrm{CO}_{3}$ & THF & 44 \\
\hline 7 & DTI2Mes & BrMes & $\mathrm{Pd}_{2}(\mathrm{dba})_{3}$ & $\mathrm{P}(2-\mathrm{MeOPh})_{3}$ & $\mathrm{Cs}_{2} \mathrm{CO}_{3}$ & DMF & 50 \\
\hline 8 & DTI2Mes & BrMes & $\mathrm{Pd}_{2}(\mathrm{dba})_{3}$ & $\mathrm{P}(2-\mathrm{MeOPh})_{3}$ & $\mathrm{Cs}_{2} \mathrm{CO}_{3}$ & Toluene & 63 \\
\hline 9 & DTI2Mes & BrMes & $\mathrm{Pd}_{2}(\mathrm{dba})_{3}$ & $\mathrm{P}(2-\mathrm{MeOPh})_{3}$ & $\mathrm{Cs}_{2} \mathrm{CO}_{3}$ & $o$-Xylene & 84 \\
\hline 10 & DTI2Cz & $\mathrm{BrCz}$ & $\mathrm{Pd}_{2}(\mathrm{dba})_{3}$ & $\mathrm{P}(2-\mathrm{MeOPh})_{3}$ & $\mathrm{Cs}_{2} \mathrm{CO}_{3}$ & $o$-Xylene & Trace \\
\hline 11 & DTI2CzR & $\mathrm{BrCzR}$ & $\mathrm{Pd}_{2}(\mathrm{dba})_{3}$ & $\mathrm{P}(2-\mathrm{MeOPh})_{3}$ & $\mathrm{Cs}_{2} \mathrm{CO}_{3}$ & $o$-Xylene & 58 \\
\hline 12 & DTI2TPA & BrTPA & $\mathrm{Pd}_{2}(\mathrm{dba})_{3}$ & $\mathrm{P}(2-\mathrm{MeOPh})_{3}$ & $\mathrm{Cs}_{2} \mathrm{CO}_{3}$ & $o$-Xylene & 72 \\
\hline 13 & DTI2F & $\mathrm{BrF}$ & $\mathrm{Pd}_{2}(\mathrm{dba})_{3}$ & $\mathrm{P}(2-\mathrm{MeOPh})_{3}$ & $\mathrm{Cs}_{2} \mathrm{CO}_{3}$ & $o$-Xylene & 61 \\
\hline 14 & DTI2Th & BrTh & $\mathrm{Pd}_{2}(\mathrm{dba})_{3}$ & $\mathrm{P}(2-\mathrm{MeOPh})_{3}$ & $\mathrm{Cs}_{2} \mathrm{CO}_{3}$ & $o$-Xylene & Trace \\
\hline 15 & DTI2Py & $\mathrm{BrPy}$ & $\mathrm{Pd}_{2}(\mathrm{dba})_{3}$ & $\mathrm{P}(2-\mathrm{MeOPh})_{3}$ & $\mathrm{Cs}_{2} \mathrm{CO}_{3}$ & $o$-Xylene & 54 \\
\hline 16 & DTI2PDI & $\mathrm{BrPDI}$ & $\mathrm{Pd}_{2}(\mathrm{dba})_{3}$ & $\mathrm{P}(2-\mathrm{MeOPh})_{3}$ & $\mathrm{Cs}_{2} \mathrm{CO}_{3}$ & $o$-Xylene & Trace \\
\hline 17 & DTI2DPP & BrDPP & $\mathrm{Pd}_{2}(\mathrm{dba})_{3}$ & $\mathrm{P}(2-\mathrm{MeOPh})_{3}$ & $\mathrm{Cs}_{2} \mathrm{CO}_{3}$ & $o$-Xylene & Trace \\
\hline 18 & DTI2NTI & BrNTI & $\mathrm{Pd}_{2}(\mathrm{dba})_{3}$ & $\mathrm{P}(2-\mathrm{MeOPh})_{3}$ & $\mathrm{Cs}_{2} \mathrm{CO}_{3}$ & $o$-Xylene & 63 \\
\hline
\end{tabular}

${ }^{a}$ The structures of ligands and palladium catalysts are shown in Figure S1. DTI (41.3 mg, $0.1 \mathrm{mmol}, 1$ equiv.), [Pd] (3 mol\%), ligand (12 mol\%), base (3.0 equiv.), pivalic acid (1 equiv.), and $0.1 \mathrm{M}$ of THF in $85^{\circ} \mathrm{C}$, DMF in $110^{\circ} \mathrm{C}$, toluene in $100^{\circ} \mathrm{C}$. and $o$-xylene in $120^{\circ} \mathrm{C}$. Isolated yield was obtained from column chromatography.

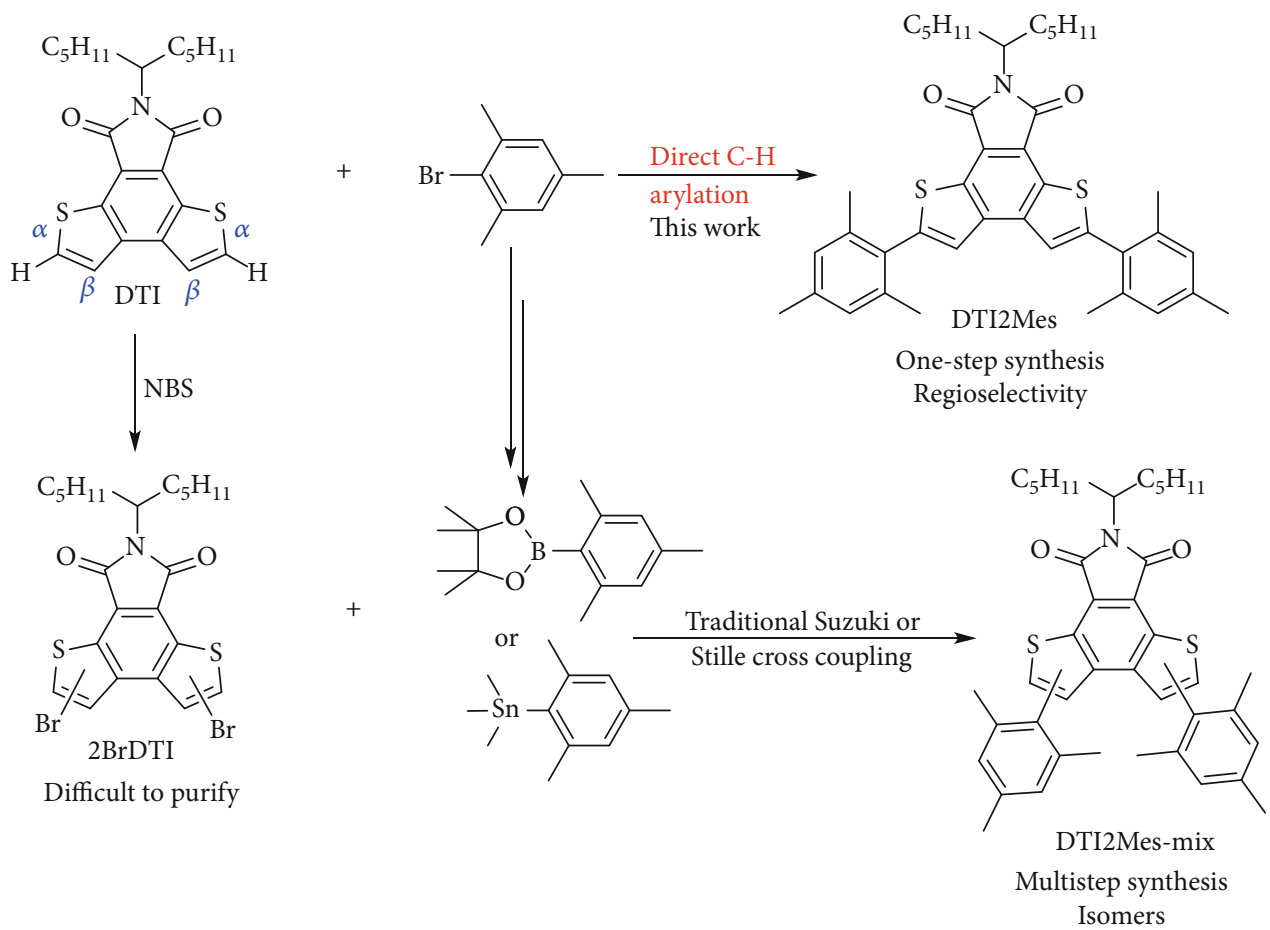

Scheme 3: The synthetic routes of DTI2Mes by direct C-H arylation as compared with those of traditional Suzuki-Stille reactions.

order to further confirm this, single-crystal X-ray diffraction (XRD) was measured to analyze the structure of DTI2Mes (Table S1). The XRD structure also shows that the reactive site of $\mathrm{C}-\mathrm{H}$ arylation based on DTI is the $\alpha$-position (Figure S3). Therefore, the direct C-H arylation based on DTI to construct $\pi$-conjugated organic molecules is not only atom- 


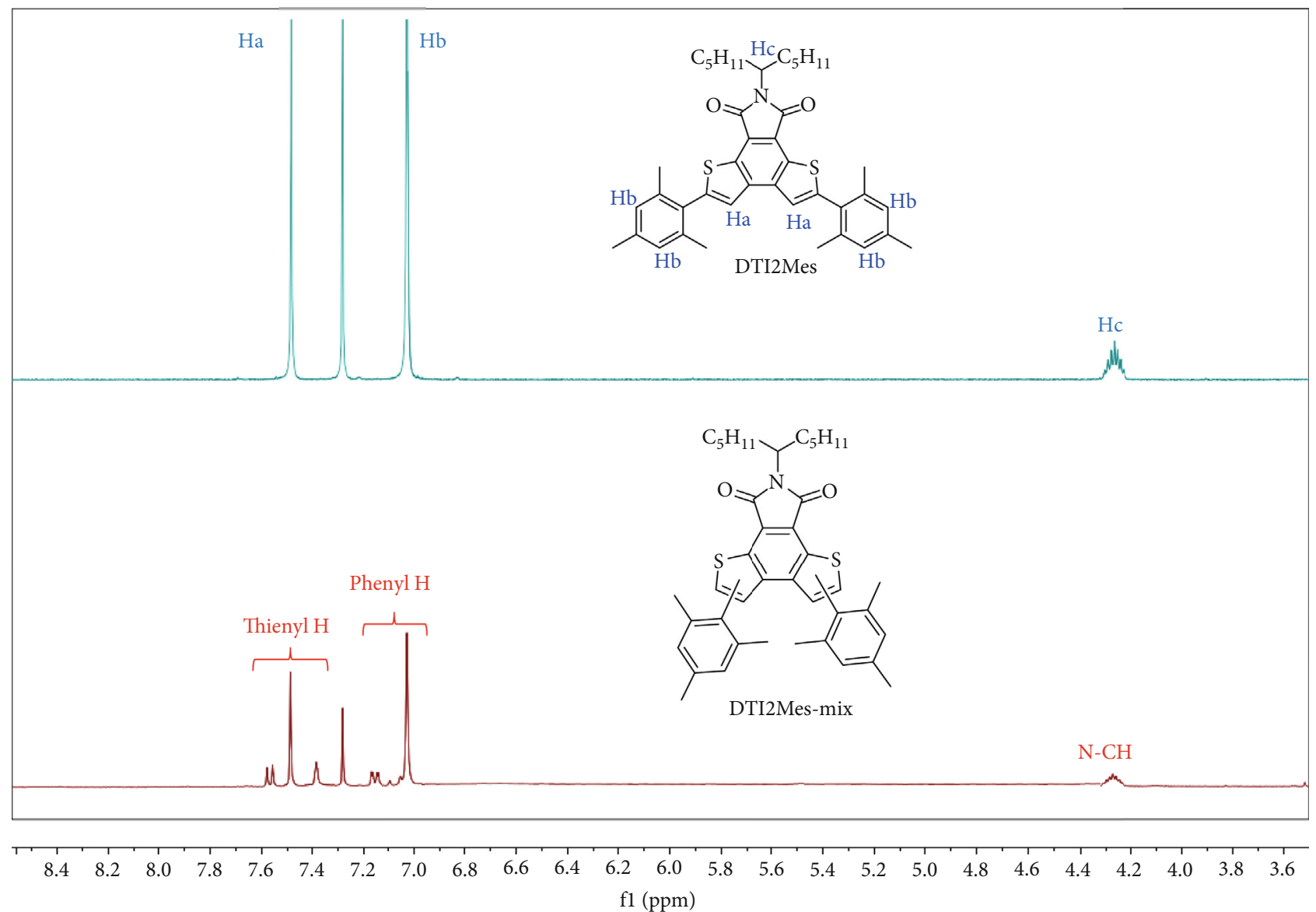

FIgURE 1: ${ }^{1} \mathrm{H}$ NMR spectra of DTI2Mes as compared with DTI2Mes-mix.

efficient and ecofriendly but also highly selective, as compared with the traditional Suzuki and Stille cross-coupling routes.

The possible mechanism for the formation of DTI-based molecules is shown in Scheme 4. The reaction mechanism studies support high regioselectivity of C-H arylation based on DTI. C-H arylation afforded $\alpha$-diarylated DTI in high yields, while traditional Suzuki and Stille cross couplings generated mixtures of $\alpha$-and $\beta$-arylated isomers due to the poor selective bromination process by NBS. The results are consistent with the reactivity profiles of electrophilic aromatic substitution via NBS bromination (Scheme S2) [60-62] but have a good correlation with a proton-transfer pathway [63-65].

To understand the reaction mechanism, a plausible palladium-catalyzed C-H arylation was performed (Scheme 4). The proposed mechanism begins with the brominated aromatic hydrocarbon $(\mathrm{BrAr})$ onto a $\mathrm{Pd}(0)$ catalyst (II). Ligand exchanges generate a bidentate carboxylate complex (III). Subsequently, the DTI substrate was deprotonated by the carboxylate base, and $\mathrm{Pd}-\mathrm{C}$ bond was formed, resulting in concerted metalation-deprotonation (CMD) state (IV). The carboxylic acids may lose coordination from the metal centers and react with a carbonate base (VII) through an acid-base reaction. Finally, new carbon-carbon bonds are formed via the reductive elimination (VIII), which regenerates the Pd (0) catalyst. The calculation showed the CMD state for the $\mathrm{C}-\mathrm{H}$ bonds on the incipient DTI (Figure 2). The activation free energy of the $\alpha$-position ( $\Delta G=32.5 \mathrm{kcal} \mathrm{mol}^{-1}$ ) of DTI is lower than that of the $\beta$-position $\left(\Delta G=35.1 \mathrm{kcal} \mathrm{mol}^{-1}\right)$, which indicates that the $\mathrm{C}-\mathrm{H}$ bond at the $\alpha$-position is more active than that at the $\beta$-position. The activation energy is lower for reactivity at the $\alpha$-position relative to the $\beta$-position, which may be due to the higher reaction activity and inherent electron bias of DTI. As such, the CMD state is regioselectivitydetermining. The computational studies support the regioselectivity of C-H arylation based on DTI. Moreover, the Mulliken charge distribution of DTI was calculated with DFT at the B3LYP/6-31G level (Figure S4). The result shows that the electronegativity of the carbon at $\alpha$-position is close to that of the carbon at the $\beta$-position. Therefore, the electrophilic substitution of DTI with NBS bromination exhibits poor selectivity.

2.3. Physical Properties of DTI-Based Materials. UV-Vis absorption spectra of the DTI-based molecules were performed to explore the influence of end groups on light-harvesting performance. The analysis results of the materials are summarized in Table 2 and Figure S5. In solutions, all the compounds exhibited two obvious absorption bands at the range of $237-345 \mathrm{~nm}$ and $377-485 \mathrm{~nm}$. The absorption bands with shorter wavelength could be attributed to localized $\pi-\pi *$ transitions of the electron-rich or electron-withdrawing groups. The longer wavelength absorption bands come from the intramolecular 


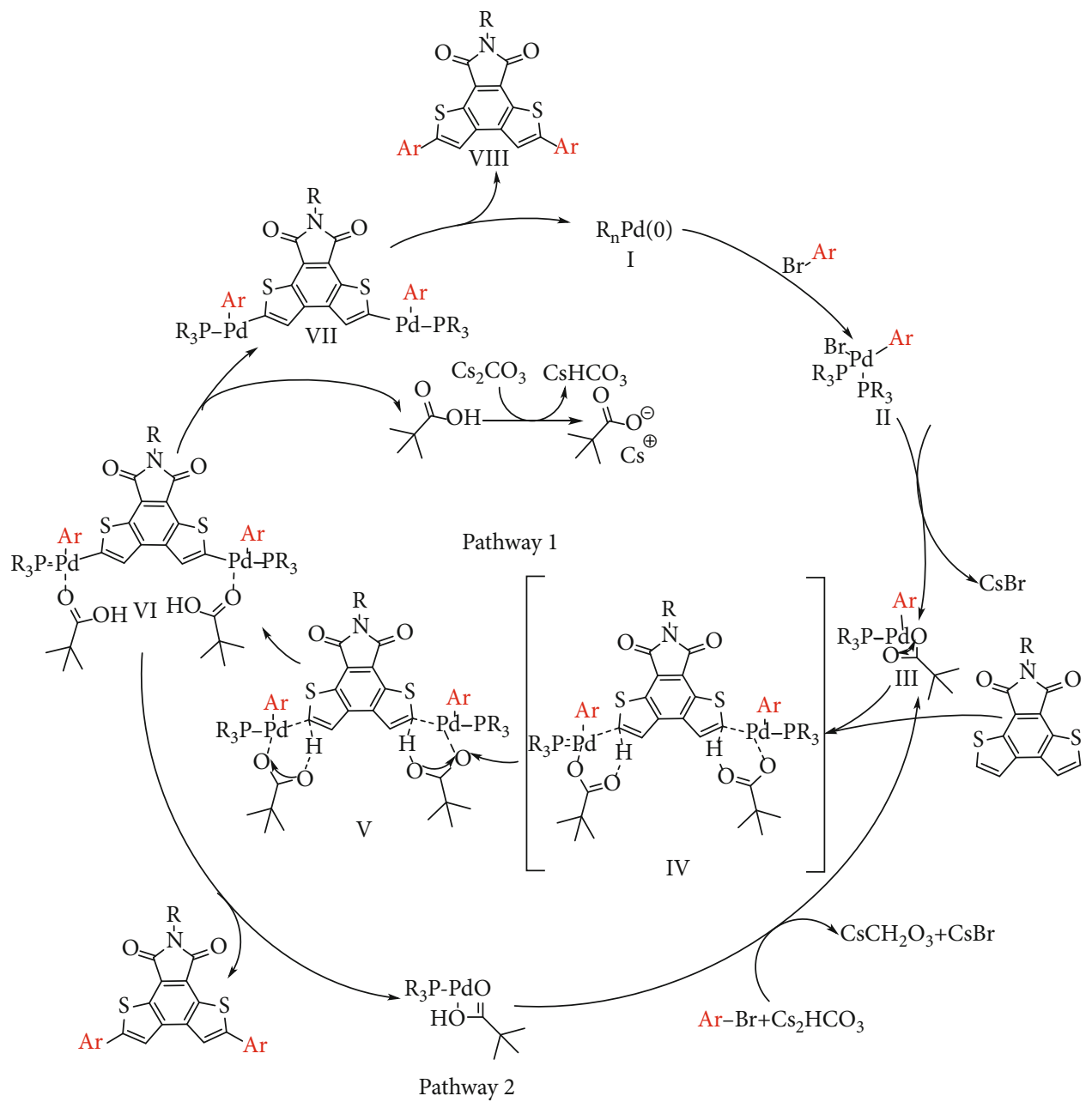

Scheme 4: Proposed mechanism for the formation of DTI-based molecules via direct C-H arylation [63-65].

charge transfer (ICT) transition between electron donor and electron acceptor [66, 67]. For all the DTI-based molecules, DTI2TPA showed the highest ICT energy band, while DTI without any substituted end group exhibited the lowest ICT energy band. In addition, the absorption spectra in thin film states showed significant red shift compared with those in solution states. The optical absorption edge $\left(\lambda_{\text {onset }}\right)$ of DTI, DTI2Mes, DTI2NTI, DTI2F, DTI2Py, DTI2CzR, and DTI2TPA shifted towards the longer wavelength and the optical band gap $\left(E_{g}^{\mathrm{opt}}\right)$ gradually decreased from $2.78 \mathrm{eV}$ to $2.17 \mathrm{eV}$. According to the results, DTI-based molecules with stronger electron-donating end groups demonstrate a larger extent of ICT characteristics, which confirm the electrondeficient nature of the DTI unit.

The emissive properties of all the DTI-based molecules were measured in solutions and in films (Figures 3(a) and 3(b)). The emission maxima of DTI, DTI2Mes, DTI2NTI, DTI2F, DTI2Py, DTI2CzR, and DTI2TPA in solutions were recorded at $460,471,497,512,541,553$, and $585 \mathrm{~nm}$, respectively, whereas those in films were at $475,483,512,539,570,597$, and $608 \mathrm{~nm}$, respectively. A little red shift in emission spectra was observed for all the DTI-based molecules (10-20 nm) upon moving from dilute solutions to thin films. The results demonstrate that the DTI-based molecules could widely modulate the photoluminescence spectra range through cross couplings with various end groups by direct $\mathrm{C}-\mathrm{H}$ arylation. As shown in Figures 3(c) and 3(d), various end group modifications on the DTI core enable the synthesis of a fluorophore library whose emission spectra cover most of the visible spectra. As shown in Table 2, much higher photoluminescence quantum yields (PLQYs) were recorded for DTI2CzR, DTI2F, and DTI2TPA as compared with those of DTI, DTI2Mes, DTI2NTI, and DTI2Py. The results show that the electron-deficient unit DTI is beneficial to the construction of a donor-acceptor-donor (D-A-D) structure and to the enhancement of ICT and luminescence. In order to further understand the photophysical properties of the obtained molecules, fluorescence decay was recorded as shown in Figure S6. The fluorescence decay times of DTI2CzR, DTI2F, and DTI2TPA in films were $4.54 \mathrm{~ns}$, $2.52 \mathrm{~ns}$, and $3.26 \mathrm{~ns}$, which were longer than those of DTI2Mes, DTI2NTI, and DTI2Py, respectively. The results suggest that $\mathrm{D}-\mathrm{A}-\mathrm{D}$ architectures can suppress the quenching of the excited singlet states, leading to the increase of delayed fluorescence and PLQYs. 


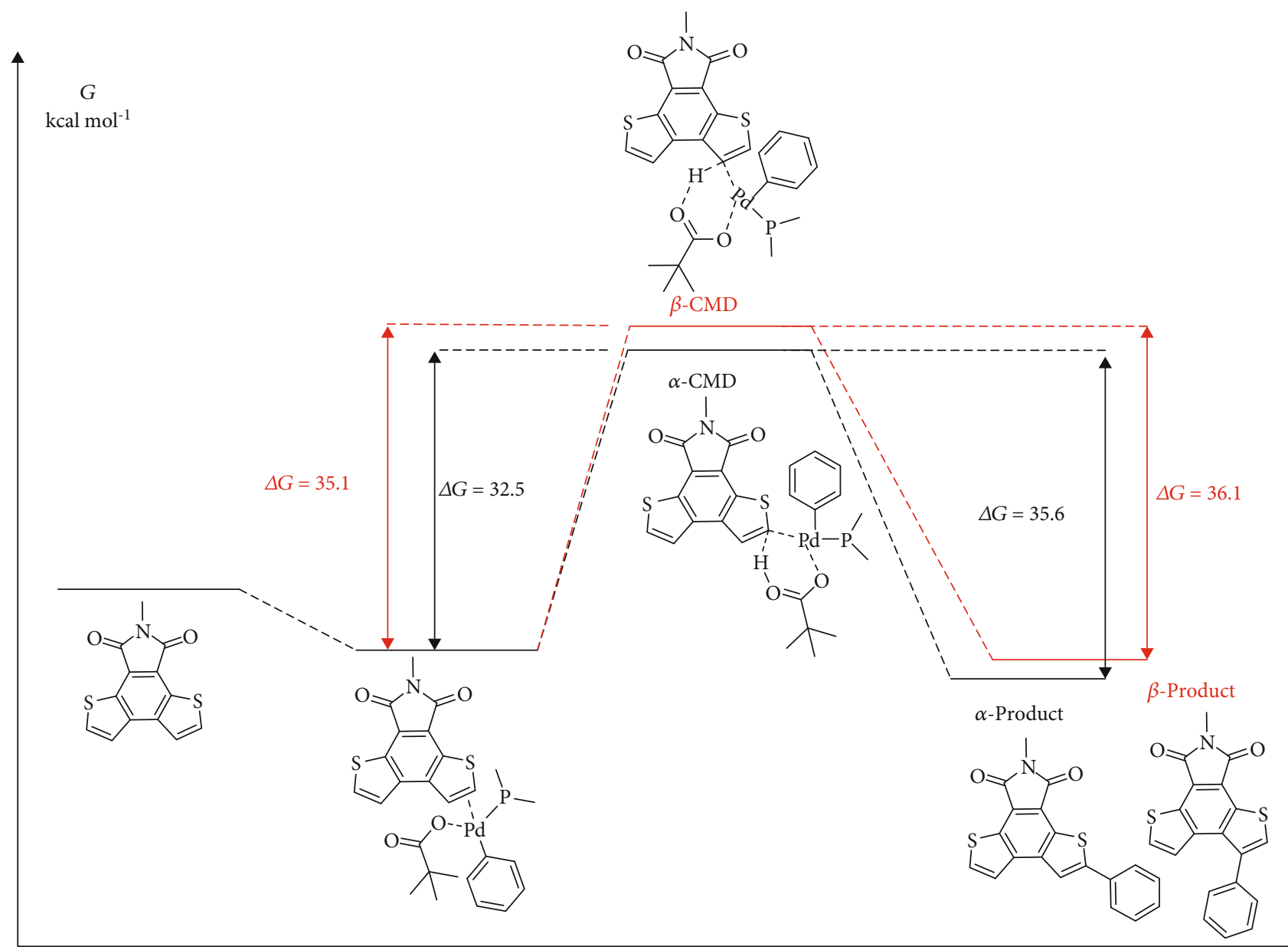

FIGURE 2: Computational study on the plausible palladium catalytic reaction of the concerted metalation-deprotonation (CMD) pathway in the gas phase.

TABLE 2: Photophysical properties of DTI-based materials.

\begin{tabular}{lccccccccc}
\hline & $\lambda_{\text {abs,solution }}(\mathrm{nm})$ & $\lambda_{\text {abs,film }}(\mathrm{nm})$ & $\lambda_{\text {onset }}(\mathrm{nm})$ & $E_{g}^{\text {opt }}(\mathrm{eV})$ & $\lambda_{\text {PL,solution }}(\mathrm{nm})$ & $\lambda_{\text {PL,film }}(\mathrm{nm})$ & $\tau_{\text {solution }}(\mathrm{ns})$ & $\tau_{\text {film }}(\mathrm{ns})$ & PLQY $(\%)$ \\
\hline DTI & 271,377 & 274,386 & 445 & 2.78 & 460 & 475 & 3.25 & 2.66 & 10 \\
DTI2Mes & 262,382 & 265,392 & 450 & 2.75 & 471 & 483 & 1.57 & 2.19 & 17 \\
DTI2NTI & 237,423 & 259,437 & 489 & 2.53 & 497 & 512 & 1.29 & 1.16 & 31 \\
DTI2F & 334,449 & 336,455 & 521 & 2.38 & 512 & 539 & 1.44 & 2.52 & 59 \\
DTI2Py & 345,444 & 354,460 & 537 & 2.31 & 541 & 570 & 1.37 & 1.43 \\
DTI2CzR & 303,468 & 310,487 & 552 & 2.24 & 553 & 597 & 4.84 & 4.54 & 67 \\
DTI2TPA & 302,485 & 306,496 & 570 & 2.17 & 585 & 608 & 4.33 & 3.26 \\
\hline
\end{tabular}

To reveal the electronic properties, electrochemical properties were studied by cyclic voltammetry (CV) (Figure S7). The results are listed in Table S2, in comparison with the calculation results with B3LYP/6-31G(d). The voltammograms revealed that the reductions were quasi reversible in most cases, but the oxidations were quite clearly irreversible in most of the voltammograms. DTI demonstrated onset oxidation potential at $1.47 \mathrm{~V}$ and the onset reduction potential at $-1.28 \mathrm{~V}$, which orresponded to the highest occupied molecular orbital (HOMO) value of $-6.10 \mathrm{eV}$ and the lowest occupied molecular orbital (LUMO) value of $-3.33 \mathrm{eV}$, respectively. The results showed that the LUMO value of DTI was significantly lower than that of its analogue dithieno[3,2-f:2 $\left.2^{\prime}, 3^{\prime}-\mathrm{h}\right]$ phthalimide $(\mathrm{LUMO}=-3.12 \mathrm{eV})$ [68], indicating that the DTI structure was easily reduced and possessed strong electron-accepting characteristics. The results were in accordance with its electron-withdrawing capacity due to the introduction of an electron-deficient aromatic imide system. DTI-based $\pi$-conjugated molecules exhibited negative shifts in oxidation potentials and little shift in the reduction potentials 


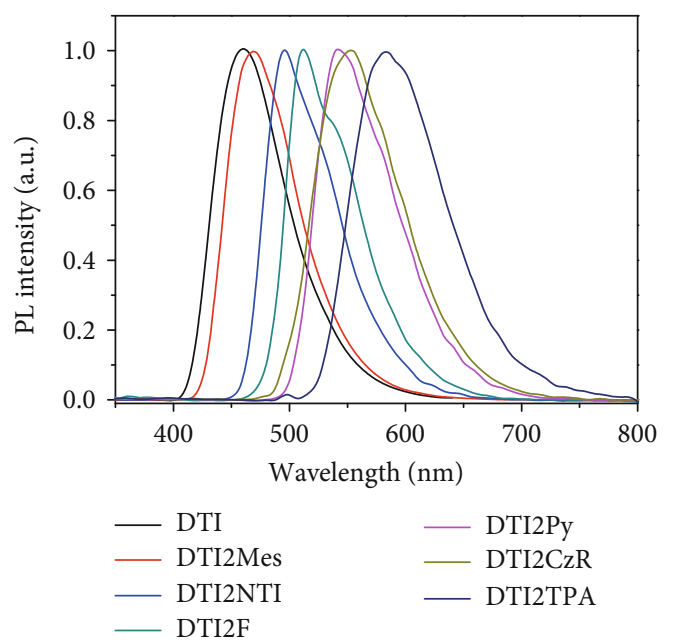

(a)

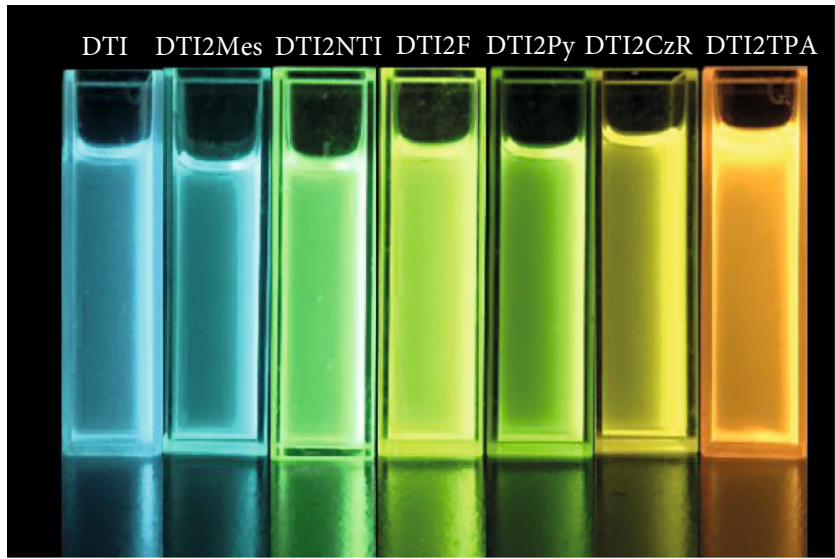

(c)

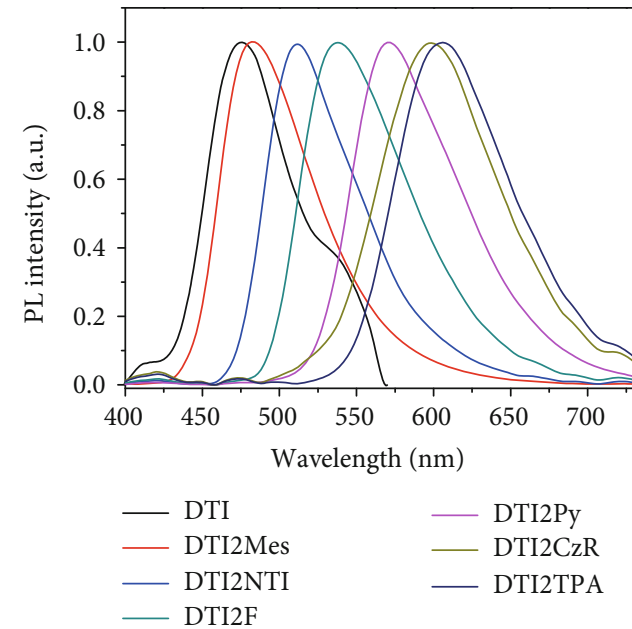

(b)

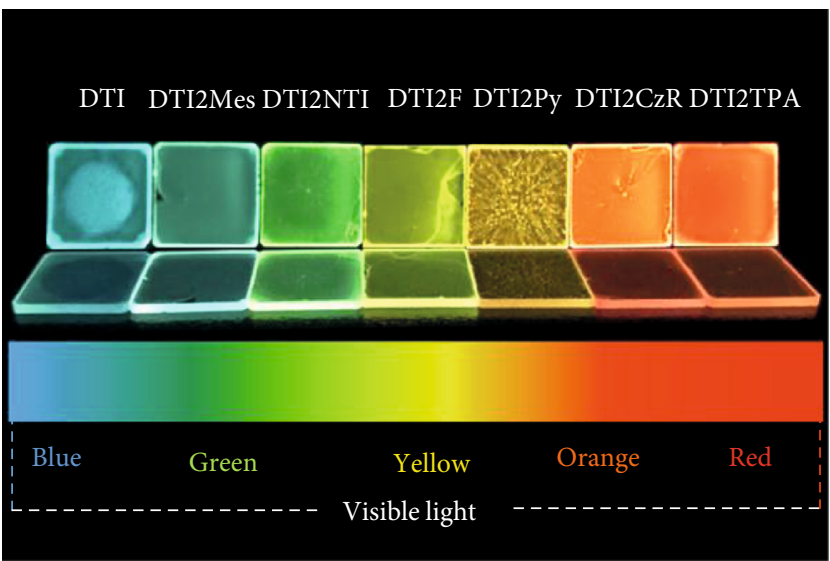

(d)

Figure 3: PL spectra of DTI-based molecules (a) in dilute DCM solutions ( $\left.c=10^{-6} \mathrm{~mol} / \mathrm{L}\right)$ and (b) in solid films; the pictures of DTI-based materials (c) in dilute DCM solutions $\left(c=10^{-6} \mathrm{~mol} / \mathrm{L}\right)$ and (d) in solid films under a UV lamp (365 nm).

as compared to those of the DTI unit. According to the results, the end groups of DTI showed little effect on LUMO energy levels but obviously raised the HOMO energy levels, leading to a considerable band gap reduction and a substantial red shift in the onset of absorption, which was consistent with the trend based on optical band gaps $\left(E_{g}^{\text {opt }}\right)$ and theoretical band gaps $\left(E_{g}^{\text {cal }}\right)$.

To better understand the effect of end groups, DFT calculations were performed on all the molecules. The optimized geometries of all the investigated molecules show planar DTI cores, which is preferred for intermolecular $\pi-\pi$ stacking. The torsion angle between the end groups and the core for DTI2Mes is $90^{\circ}$ owing to the extra bulkiness of mesitylene (Figure S8). However, the geometry of DTI2F and DTI2CzR is almost planar, which increases the conjugation of these molecules. Based on the predicted ground state structure with global minimum energies, the time-dependent (TD) DFT simulation was carried out by TD-B3LYP/6-31G, and the optical and electronic properties of DTI and its derivatives were calculated (Figure 4). Most of the molecules show extensively delocalized HOMO and LUMO spatial distributions, except for DTI2Mes that shows vertical structure between DTI and mesitylene unit. There is little overlap between HOMO and LUMO for DTI2CzR and DTI2TPA, indicating that large intramolecular charger transfer occurs. Despite the comparable torsion angles, the aryl substituents had a great impact on the energy levels of DTI, gradually raising the HOMO energy level from $-6.09 \mathrm{eV}$ to $-5.06 \mathrm{eV}$. The trend of the theoretical band gap and HOMO energy levels for DTI-based molecules was similar to that of $\mathrm{CV}$ measurements.

2.4. OLED Performance of DTI2F and DTI2CzR. With achieving excellent solid-state fluorescence and high PLQYs of DTI2F and DTI2CzR, the potential application of these molecules in OLEDs was investigated. A set of unoptimized OLEDs based on DTI2F (device I) and DTI2CzR (device II) was fabricated by solution processing. A single-emissive-layer OLED with the configuration ITO/PEDOT:PSS $(40 \mathrm{~nm}) / \mathrm{DTI} 2 \mathrm{~F}$ or DTI2CzR/TmPyPB 


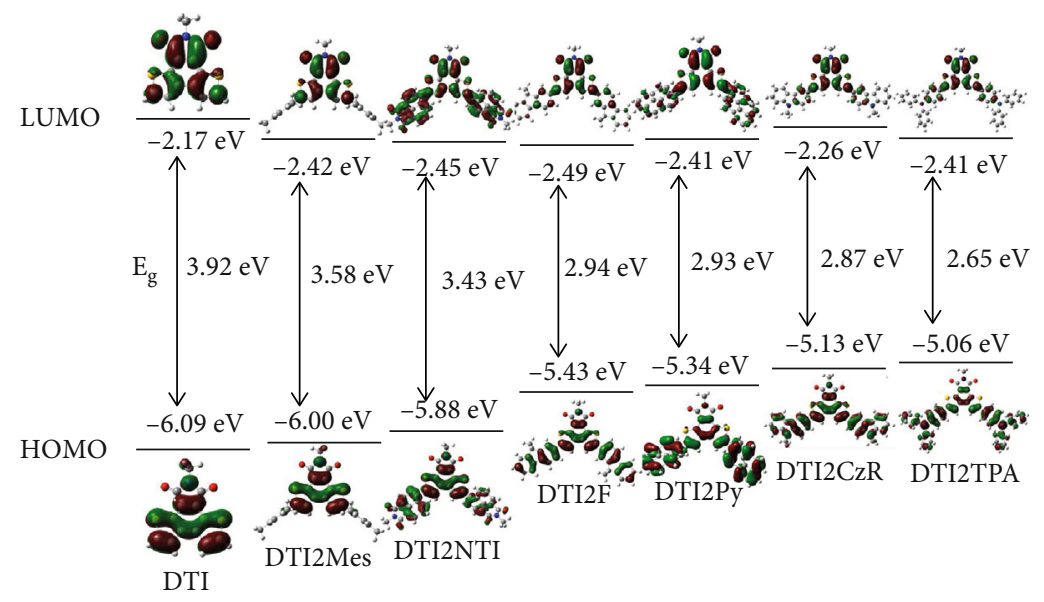

Figure 4: The calculated electron cloud distribution of DTI-based molecules with DFT at the B3LYP/6-31G level.

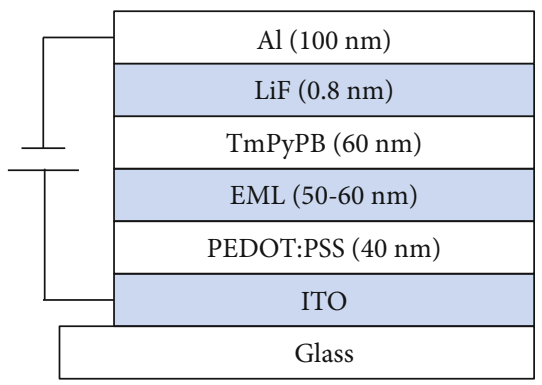

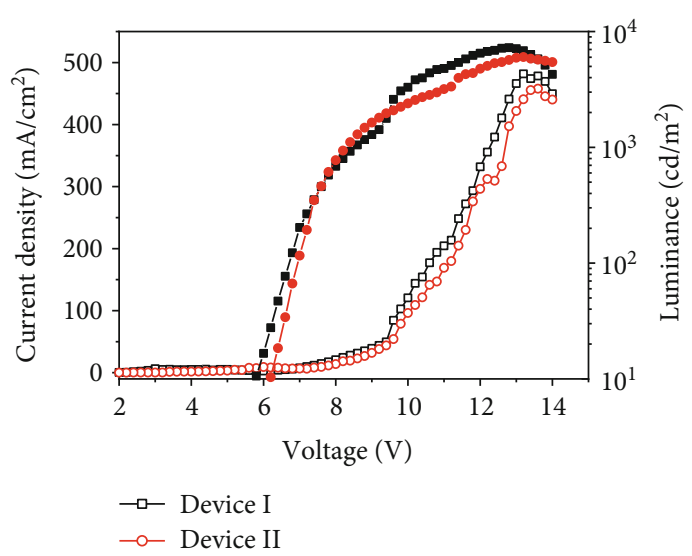

(b)

FIGURE 5: (a) OLED configuration and (b) current density-voltage (open symbols) and luminance-voltage (solid symbols) curve characteristics of the devices based on DTI2F and DTI2CzR.

$(60 \mathrm{~nm}) / \mathrm{LiF} \quad(0.8 \mathrm{~nm}) / \mathrm{Al} \quad(100 \mathrm{~nm}) \quad$ was fabricated (Figure 5(a)). PEDOT:PSS was spin-coated on ITO substrates and annealed at $150^{\circ} \mathrm{C}$ for $60 \mathrm{~min}$. DTI2F and DTI2CzR film was coated onto PEDOT:PSS film with a thickness of $50-60 \mathrm{~nm}$ from toluene solution. Then, TmPyPB, LiF, and $\mathrm{Al}$ were consecutively deposited onto the emission layer. The EL spectra of devices I and II are shown in Figure S9, and the maximum emission peaks at $535 \mathrm{~nm}$ and $590 \mathrm{~nm}$ for DTI2F and DTI2CzR, respectively, which are similar to their photoluminescence data in solid films. As shown in Figure 5(b), the maximum brightness of device $\mathrm{I}$ is $7200 \mathrm{~cd} / \mathrm{m}^{2}$ at $11 \mathrm{~V}$, which is higher than that of device II $\left(6100 \mathrm{~cd} / \mathrm{m}^{2}\right.$ at $11 \mathrm{~V})$. The maximum current efficient is $3.8 \mathrm{~cd} / \mathrm{A}$ and $3.2 \mathrm{~cd} / \mathrm{A}$ for devices I and II, respectively (Figure S10). The simple device structures demonstrate good OLED performances, indicating that direct $\mathrm{C}-\mathrm{H}$ arylation is feasible and powerful to construct DTI-based molecules as promising active materials for organic optoelectronic applications.

\section{Discussion}

In this work, we have developed a facile selective direct $\mathrm{C}-\mathrm{H}$ arylation methodology for efficient construction of a variety of symmetrical DTI-based $\pi$-conjugated molecules. The resulting methodology is effective and applicable for a wide range of substrates from electron-rich units to electrondeficient units with large steric end groups. In addition, direct $\mathrm{C}-\mathrm{H}$ arylation of DTI is highly selective and ecofriendly as compared with the traditional Suzuki or Stille crosscoupling routes. Aryl halides have been confirmed to be able to couple with DTI via direct $\mathrm{C}-\mathrm{H}$ arylation, showing high regioselectivity. According to this green methodology, various symmetrical new conjugated molecules based on DTI were successfully synthesized in a one-pot procedure, affording good to excellent yields. Varying the functional end groups onto the DTI core has been demonstrated to fine tune the emission colors to cover most of the visible spectra, which are potential active materials for organic optoelectronics, i.e., OLEDs. According to these photophysical and 
eletrochemical properties, the conjugated molecules are good candidates for high-performance solution-processable optoelectronic devices. Preliminary OLED measurements show that devices based on DTI2F and DTI2CzR achieved a maximum brightness of $7200 \mathrm{~cd} / \mathrm{m}^{2}$ and $6100 \mathrm{~cd} / \mathrm{m}^{2}$, respectively. The results suggest a facile strategy towards highly selective direct $\mathrm{C}$ - $\mathrm{H}$ arylation for the efficient construction of $\pi$-conjugated molecules for organic optoelectronic applications.

\section{Conflicts of Interest}

The authors declare that there are no conflicts of interest regarding the publication of this article.

\section{Authors' Contributions}

Xiang-Chun Li, Wen-Yong Lai, and Wei Huang conceived the idea and designed the experiments; Xiang-Chun Li and Yibo Xue conducted the experiments; Wan Song and Yu Yan obtained key single crystals and conducted X-ray structural analysis; Jie Min and Fang Liu did the device fabrication and measurement; $\mathrm{Xu}$ Liu did the CV tests; and Xiang-Chun Li, Yibo Xue, and Wen-Yong Lai analyzed and discussed the data. Xiang-Chun Li and Yibo Xue made the draft, Wen-Yong Lai revised the manuscript, and all the authors contributed to the writing of the manuscript. Xiang-Chun Li and Yibo Xue contributed equally to this work.

\section{Acknowledgments}

We acknowledge the financial support from the National Natural Science Foundation of China (21835003, 21674050, 91833304, 21422402, and 61704077), the National Basic Research Program of China (973 Program) (2017YFB0404501 and 2014CB648300), the China Postdoctoral Science Foundation (2019M650121, 2020M671553, 2016M601784, 2017M620519, and 2017T100358), the Natural Science Foundation of Jiangsu Province (BE2019120), the Program for Jiangsu Specially Appointed Professor (RK030STP15001), the Postdoctoral Science Foundation of Jiangsu Province (1701135B), the Six Talent Peaks Project in Jiangsu Province (TD-XCL-009), the 333 Project of Jiangsu Province (BRA2017402), the NUPT "1311 Project" and Scientific Foundation (NY217169, NY219021, NY215062, and NY217087), the Leading Talent of Technological Innovation of National Ten-Thousands Talents Program of China, the Excellent Scientific and Technological Innovative Teams of Jiangsu Higher Education Institutions (TJ217038), the Priority Academic Program Development of Jiangsu Higher Education Institutions (PAPD), and the Synergetic Innovation Center for Organic Electronics and Information Displays.

\section{Supplementary Materials}

Figure S1: structures of commonly used palladium catalysts and ligands in direct C-H arylation. Scheme S1: synthesis of DTI. Scheme S2: brominated reaction mechanism of DTI in the presence of NBS. Figure S2: the experimental and theoret- ical ${ }^{1} \mathrm{H}$ NMR spectra of 2BrDTI. Table S1: crystallographic data for DTI2Mes. Figure S3: oak ridge thermal ellipsoid plot (ORTEP) view of the molecular structures and packing structure of DTI2Mes. Figure S4: the Mulliken charge distribution of DTI. Figure S5: (a) UV-Vis absorption of DTI-based conjugated molecules in dilute DCM solutions (10-6 M) and (b) in the films spin-cast on quartz. Figure S6: (a) fluorescent lifetime tests of DTI-based conjugated molecules in dilute DCM olutions (10-6 M) and (b) in the spin-coated films. Table S2: CV data for DTI-based conjugated molecules. Figure S7: cyclic voltammogram $(\mathrm{CV})$ curves of DTI-based molecules. Figure S8: side views of the optimized geometries obtained from DFT calculations at the B3LYP/6-31G level. Figure S9: electroluminescence (EL) spectra of the devices based on DTI2F and DTI2CzR. Figure S10: (a) current efficiency-current density curves and (b) EQE-current density curves of the devices based on DTI2F and DTI2CzR. Figures S11-S32: MALDITOF mass spectra, ${ }^{1} \mathrm{H}$ NMR, and $13 \mathrm{C}$ NMR of the synthesized compounds. (Supplementary Materials)

\section{References}

[1] L. Gu, H. Shi, L. Bian et al., "Colour-tunable ultra-long organic phosphorescence of a single-component molecular crystal," Nature Photonics, vol. 13, no. 6, pp. 406-411, 2019.

[2] Z. An, C. Zheng, Y. Tao et al., "Stabilizing triplet excited states for ultralong organic phosphorescence," Nature Materials, vol. 14, no. 7, pp. 685-690, 2015.

[3] L.-H. Xie, C.-R. Yin, W.-Y. Lai, Q.-L. Fan, and W. Huang, "Polyfluorene-based semiconductors combined with various periodic table elements for organic electronics," Progress in Polymer Science, vol. 37, no. 9, pp. 1192-1264, 2012.

[4] N. B. Kotadiya, P. W. Blom, and G.-J. A. Wetzelaer, "Efficient and stable single-layer organic light-emitting diodes based on thermally activated delayed fluorescence," Nature Photonics, vol. 13, no. 11, pp. 765-769, 2019.

[5] Y. Kondo, K. Yoshiura, S. Kitera et al., "Narrowband deepblue organic light-emitting diode featuring an organoboronbased emitter," Nature Photonics, vol. 13, no. 10, pp. 678682, 2019.

[6] Y. Tao, X. Guo, L. Hao et al., “A solution-processed resonance host for highly efficient electrophosphorescent devices with extremely low efficiency roll-off," Advanced Materials, vol. 27, no. 43, pp. 6939-6944, 2015.

[7] W.-Y. Lai, Q. Y. He, R. Zhu, Q. Q. Chen, and W. Huang, "Kinked star-shaped fluorene/triazatruxene co-oligomer hybrids with enhanced functional properties for high-performance, solutionprocessed, blue organic light-emitting diodes," Advanced Functional Materials, vol. 18, no. 2, pp. 265-276, 2008.

[8] H. Fu, Z. Wang, and Y. Sun, "Polymer donors for highperformance non-fullerene organic solar cells," Angewandte Chemie International Edition, vol. 58, no. 14, pp. 4442-4453, 2019.

[9] W. Xu, R. Xia, T. Ye et al., "Understanding the light soaking effects in inverted organic solar cells functionalized with conjugated macroelectrolyte electron-collecting interlayers," Advanced Science, vol. 3, no. 2, article 1500245, 2016.

[10] J. Yuan, Y. Zhang, L. Zhou et al., "Fused benzothiadiazole: A building block for n-type organic acceptor to achieve highperformance organic solar cells," Advanced Materials, vol. 31, no. 17 , article $1807577,2019$. 
[11] C. F. Liu, X. Liu, W.-Y. Lai, and W. Huang, "Organic lightemitting field-effect transistors: device geometries and fabrication techniques," Advanced Materials, vol. 30, no. 52, article 1802466, 2018.

[12] H. Chen, A. Wadsworth, C. Ma et al., "The effect of ring expansion in thienobenzo [b] indacenodithiophene polymers for organic field-effect transistors," Journal of the American Chemical Society, vol. 141, no. 47, pp. 18806-18813, 2019.

[13] Z. Jin, Z. F. Yao, K. P. Barker, J. Pei, and Y. Xia, "Dinaphthobenzo $[1,2: 4,5]$ dicyclobutadiene: antiaromatic and orthogonally tunable electronics and packing," Angewandte Chemie International Edition, vol. 131, no. 7, pp. 2056-2061, 2019.

[14] F. D. Zhuang, Z. H. Sun, Z. F. Yao et al., "BN-embedded tetrabenzopentacene: a pentacene derivative with improved stability," Angewandte Chemie International Edition, vol. 131, no. 31, pp. 10818-10822, 2019.

[15] W. Xu, J. Yi, W.-Y. Lai et al., "Pyrene-capped conjugated amorphous starbursts: synthesis, characterization, and stable lasing properties in ambient atmosphere," Advanced Functional Materials, vol. 25, no. 29, pp. 4617-4625, 2015.

[16] Y. Jiang, P. Lv, J. Q. Pan et al., "Low-threshold organic semiconductor lasers with the aid of phosphorescent Ir(III) complexes as triplet sensitizers," Advanced Functional Materials, vol. 29, no. 19, article 1806719, 2019.

[17] J. Shang, C. Cong, Z. Wang et al., "Room-temperature 2D semiconductor activated vertical-cavity surface-emitting lasers," Nature Communications, vol. 8, no. 1, p. 543, 2017.

[18] C.-F. Liu, M. Sang, W.-Y. Lai, T. T. Lu, X. Liu, and W. Huang, "Design and synthesis of monodisperse macromolecular starbursts based on a triazine center with multibranched oligofluorenes as efficient gain media for organic lasers," Macromolecules, vol. 51, no. 4, pp. 1325-1335, 2018.

[19] W.-Y. Lai, R. Xia, Q. Y. He, P. A. Levermore, W. Huang, and D. D. C. Bradley, "Enhanced solid-state luminescence and low-threshold lasing from starburst macromolecular materials," Advanced Materials, vol. 21, no. 3, pp. 355360, 2009.

[20] K. Kenry, C. Chong, and B. Liu, "Reactivity-based organic theranostic bioprobes," Accounts of Chemical Research, vol. 52, no. 11, pp. 3051-3063, 2019.

[21] Z. Yang, Y. Dai, C. Yin et al., "Activatable semiconducting theranostics: Simultaneous generation and ratiometric photoacoustic imaging of reactive oxygen species in vivo," Advanced Materials, vol. 30, no. 23, article 1707509, 2018.

[22] Y. Cao, J.-H. Dou, N.-j. Zhao et al., "Highly efficient NIR-II photothermal conversion based on an organic conjugated polymer," Chemistry of Materials, vol. 29, no. 2, pp. 718-725, 2017.

[23] T. Rogge and L. Ackermann, "Arene-free ruthenium (II/IV)catalyzed bifurcated arylation for oxidative C-H/C-H functionalizations," Angewandte Chemie International Edition, vol. 58, no. 44, pp. 15640-15645, 2019.

[24] B. Jiang and W.-H. Zhu, "Unexpected synthesis of structuretunable aie-active acrylonitriles by simple temperature variation for bioimaging," Science China Chemistry, vol. 62, no. 12, pp. 1549-1550, 2019.

[25] H. Sun, S. Liu, W. Lin et al., "Smart responsive phosphorescent materials for data recording and security protection," Nature Communications, vol. 5, no. 1, p. 3601, 2014.

[26] W. Xu, Q. Hu, S. Bai et al., "Rational molecular passivation for high-performance perovskite light-emitting diodes," Nature Photonics, vol. 13, no. 6, pp. 418-424, 2019.
[27] X.-C. Li, Y.-G. Tu, C. Meng et al., "Diindolotriazatruxenebased hole-transporting materials for high-efficiency planar perovskite solar cells," ACS Applied Materials \& Interfaces, vol. 11, no. 49, pp. 45717-45725, 2019.

[28] B. Kan, M. Li, Q. Zhang et al., "A series of simple oligomer-like small molecules based on oligothiophenes for solutionprocessed solar cells with high efficiency," Journal of the American Chemical Society, vol. 137, no. 11, pp. 3886-3893, 2015.

[29] W. Wang, M. M. Lorion, J. Shah, A. R. Kapdi, and L. Ackermann, "Late-stage peptide diversification by position-selective C-H activation," Angewandte Chemie International Edition, vol. 57, no. 45, pp. 14700-14717, 2018.

[30] F. Lv and Z.-J. Yao, "Recent advances in direct dehydrogenative biphenyl couplings," Science China-Chemistry, vol. 60, no. 6, pp. 701-720, 2017.

[31] E. A. Fernández, M. A. Rivero-Crespo, I. Domínguez et al., "Base-controlled Heck, Suzuki, and Sonogashira reactions catalyzed by ligand-free platinum or palladium single atom and sub-nanometer clusters," Journal of the American Chemical Society, vol. 141, no. 5, pp. 1928-1940, 2019.

[32] Y.-B. Zhou, Y.-Q. Wang, L.-C. Ning et al., "Conjugated microporous polymer as heterogeneous ligand for highly selective oxidative Heck reaction," Journal of the American Chemical Society, vol. 139, no. 11, pp. 3966-3969, 2017.

[33] F. Wang, X.-C. Li, W.-Y. Lai, Y. Chen, W. Huang, and F. Wudl, "Synthesis and characterization of symmetric cyclooctatetraindoles: exploring the potential as electron-rich skeletons with extended $\pi$-systems," Organic Letters, vol. 16, no. 11, pp. 2942-2945, 2014.

[34] Y. Segawa, T. Maekawa, and K. Itami, "Synthesis of extended $\pi$-systems through C-H activation," Angewandte Chemie International Edition, vol. 54, no. 1, pp. 66-81, 2015.

[35] H. Bohra and M. Wang, "Direct C-H arylation: a "Greener" approach towards facile synthesis of organic semiconducting molecules and polymers," Journal of Materials Chemistry A, vol. 5, no. 23, pp. 11550-11571, 2017.

[36] N. S. Gobalasingham and B. C. Thompson, "Direct arylation polymerization: A guide to optimal conditions for effective conjugated polymers," Progress in Polymer Science, vol. 83, pp. 135-201, 2018.

[37] Z. Guo, L. Shi, B. Wang, G. He, Y. Wang, and G. Chen, "Synthesis of reversible pad4 inhibitors via copper-catalyzed C-H arylation of benzimidazole," Science China-Chemistry, vol. 62 , no. 5, pp. 592-596, 2019.

[38] H. Wei, H. Lu, T. Fang, and Z. Bo, "Evaluating the photovoltaic properties of two conjugated polymers synthesized by Suzuki polycondensation and direct C-H activation," Science China-Chemistry, vol. 58, no. 2, pp. 286-293, 2015.

[39] Y. Ren and W. Su, "Cu-catalyzed enantioselective cyanation of benzylic C-H via radical relay,” Science Bulletin, vol. 61, no. 23, pp. 1791-1792, 2016.

[40] A. Suzuki, "Carbon-carbon bonding made easy," Chemical Communications, vol. 38, no. 38, pp. 4759-4763, 2005.

[41] P. Espinet and A. M. Echavarren, "The mechanisms of the Stille reaction," Angewandte Chemie International Edition, vol. 43, no. 36, pp. 4704-4734, 2004.

[42] J. Zhang, W. Chen, A. J. Rojas et al., "Controllable direct arylation: fast route to symmetrical and unsymmetrical 4,7-diaryl5,6-difluoro-2,1,3-benzothiadiazole derivatives for organic optoelectronic materials," Journal of the American Chemical Society, vol. 135, no. 44, pp. 16376-16379, 2013. 
[43] A.-J. Payne, J. Song, Y. Sun, and G. C. Welch, "A tetrameric perylene diimide non-fullerene acceptor via unprecedented direct (hetero) arylation cross-coupling reactions," Chemical Communications, vol. 54, no. 81, pp. 11443-11446, 2018.

[44] J. Guo, H. He, Z. Ye, K. Zhu, Y. Wu, and F. Zhang, "Highly selective palladium-catalyzed arene $\mathrm{C}-\mathrm{H}$ acyloxylation with benzothiadiazole as a modifiable directing group," Organic Letters, vol. 20, no. 18, pp. 5692-5695, 2018.

[45] L. E. McNamara, N. Liyanage, A. Peddapuram, J. S. Murphy, J. H. Delcamp, and N. I. Hammer, "Donor-acceptor-donor thienopyrazines via Pd-catalyzed $\mathrm{C}-\mathrm{H}$ activation as NIR fluorescent materials," The Journal of Organic Chemistry, vol. 81, no. 1, pp. 32-42, 2016.

[46] A. Ichige, H. Saito, J. Kuwabara, T. Yasuda, J.-C. Choi, and T. Kanbara, "Facile synthesis of thienopyrroledione-based $\pi$ conjugated polymers via direct arylation polycondensation under aerobic conditions," Macromolecules, vol. 51, no. 17, pp. 6782-6788, 2018.

[47] S. I. Gorelsky, "Origins of regioselectivity of the palladiumcatalyzed (aromatic) CH bond metalation-deprotonation," Coordination Chemistry Reviews, vol. 257, no. 1, pp. 153164, 2013.

[48] L.-C. Campeau, M. Bertrand-Laperle, J.-P. Leclerc, E. Villemure, S. Gorelsky, and K. Fagnou, "C2, C5, and C4 azole $\mathrm{N}$-oxide direct arylation including room-temperature reactions," Journal of the American Chemical Society, vol. 130, no. 11, pp. 3276-3277, 2008.

[49] I. B. Perry, T. F. Brewer, P. J. Sarver, D. M. Schultz, D. A. DiRocco, and D. W. MacMillan, "Direct arylation of strong aliphatic C-H bonds," Nature, vol. 560, no. 7716, pp. 70-75, 2018.

[50] K. Hirano and M. Miura, "A lesson for site-selective C-H functionalization on 2-pyridones: radical, organometallic, directing group and steric controls," Chemical Science, vol. 9, no. 1, pp. 22-32, 2018.

[51] Y. Yang, P. Gao, Y. Zhao, and Z. Shi, "Regiocontrolled direct $\mathrm{C}-\mathrm{H}$ arylation of indoles at the $\mathrm{C} 4$ and $\mathrm{C} 5$ positions," Angewandte Chemie International Edition, vol. 56, no. 14, pp. 3966-3971, 2017.

[52] S. Li, H. Wang, Y. Weng, and G. Li, "Carboxy group as a remote and selective chelating group for $\mathrm{C}-\mathrm{H}$ activation of arenes," Angewandte Chemie International Edition, vol. 131, no. 51, pp. 18673-18678, 2019.

[53] M. Shigenobu, K. Takenaka, and H. Sasai, "Palladium-catalyzed direct $\mathrm{C}-\mathrm{H}$ arylation of isoxazoles at the 5-position," Angewandte Chemie International Edition, vol. 54, no. 33, pp. 9572-9576, 2015.

[54] F. Lombeck, F. Marx, K. Strassel et al., "To branch or not to branch: C-H selectivity of thiophene-based donor-acceptordonor monomers in direct arylation polycondensation exemplified by PCDTBT," Polymer Chemistry, vol. 8, no. 32, pp. 4738-4745, 2017.

[55] J. T. Blaskovits, P. A. Johnson, and M. Leclerc, "Mechanistic origin of $\beta$-defect formation in thiophene-based polymers prepared by direct (hetero) arylation," Macromolecules, vol. 51, no. 20, pp. 8100-8113, 2018.

[56] A. E. Rudenko, A. A. Latif, and B. C. Thompson, "Influence of $\beta$-linkages on the morphology and performance of DArP P3HT-PC ${ }_{61}$ BM solar cells," Nanotechnology, vol. 25, no. 1, article 014005, 2013.

[57] A. Sagadevan and M. F. Greaney, "Meta-selective C-H activation of arenes at room temperature using visible light: dual- function ruthenium catalysis," Angewandte Chemie International Edition, vol. 131, no. 29, pp. 9931-9935, 2019.

[58] B. Li, B. Lawrence, G. Li, and H. Ge, "Ligand-controlled direct $\gamma$-C-H arylation of aldehydes," Angewandte Chemie International Edition, vol. 59, no. 8, pp. 3078-3082, 2020.

[59] M. Jurrat, L. Maggi, W. Lewis, and L. T. Ball, "Modular bismacycles for the selective C-H arylation of phenols and naphthols," Nature Chemistry, vol. 12, no. 3, pp. 260-269, 2020.

[60] D. A. Guthrie and J. D. Tovar, "Conformation as a protecting group: a regioselective aromatic bromination en route to complex $\pi$-electron systems," Organic Letters, vol. 10, no. 19, pp. 4323-4326, 2008.

[61] I. Saikia, A. J. Borah, and P. Phukan, "Use of bromine and bromo-organic compounds in organic synthesis," Chemical Reviews, vol. 116, no. 12, pp. 6837-7042, 2016.

[62] R. M. Kellogg, A. P. Schaap, E. T. Harper, and H. Wynbert, "Acid-catalyzed brominations, deuterations, rearrangements, and debrominations of thiophenes under mild conditions," The Journal of Organic Chemistry, vol. 33, no. 7, pp. 2902 2909, 1968.

[63] M. Lafrance and K. Fagnou, "Palladium-catalyzed benzene arylation: incorporation of catalytic pivalic acid as a proton shuttle and a key element in catalyst design," Journal of the American Chemical Society, vol. 128, no. 51, pp. 1649616497, 2006.

[64] M. Lafrance, C. N. Rowley, T. K. Woo, and K. Fagnou, "Catalytic intermolecular direct arylation of perfluorobenzenes," Journal of the American Chemical Society, vol. 128, no. 27, pp. 8754-8756, 2006.

[65] L. G. Mercier and M. Leclerc, "Direct (hetero)arylation: a new tool for polymer chemists," Accounts of Chemical Research, vol. 46, no. 7, pp. 1597-1605, 2013.

[66] S. K. Lee, J. M. Cho, Y. Goo et al., "Synthesis and characterization of a thiazolo[5, 4-d]thiazole-based copolymer for high performance polymer solar cells," Chemical Communications, vol. 47, no. 6, pp. 1791-1793, 2011.

[67] M. M. Wienk, M. Turbiez, J. Gilot, and R. A. Janssen, "Narrow-bandgap diketo-pyrrolo-pyrrole polymer solar cells: The effect of processing on the performance," Advanced Materials, vol. 20, no. 13, pp. 2556-2560, 2008.

[68] H. Wang, Q. Shi, Y. Lin et al., "Conjugated polymers based on a new building block: dithienophthalimide," Macromolecules, vol. 44, no. 11, pp. 4213-4221, 2011. 